\title{
Shift Work and Extended Working Hours as Risk Factors for Occupational Injury
}

\author{
Simo Salminen*
}

Finnish Institute of Occupational Health, Helsinki, Finland

\begin{abstract}
The aim of this review is to examine the effect of shift work and extended working hours on occupational injuries. A calculation based on four studies shows that the risk of occupational injury during afternoon shifts was $6 \%$ lower than that during morning shifts. The same kind of calculation showed that the risk of occupational injury during night shifts was $15 \%$ lower than during morning shifts. A review of eight studies showed that the risk of occupational injury was $41 \%$ higher for 10 -hour working days compared to 8 -hour working days. On the other hand, working 12-hour days increased the risk of occupational injury by $14 \%$. When working more than 12 hours per day, three studies showed a $98 \%$ increase in involvement in occupational injury. The results of this study showed that shift work considerably increased the risk of occupational injury in the USA, but not in the other countries. Extended working hours was related to elevated risk of occupational injury. Thus shift work and long work hours did not suit for all employees.
\end{abstract}

Keywords: Shift work, long working hours, occupational accidents, review.

\section{INTRODUCTION}

Success in global markets requires companies to be flexible and ready to make rapid changes. For workers, this can mean an increasing amount of shift work or extended working days. The aim of this review is to examine whether these factors (shift work, extended working days and breaks) are related to occupational injuries.

\section{METHODS}

For this literature review, the studies were collected on the following criteria:

1) The studies were published, most of them in peerreviewed journals. All the studies reviewed were published in English.

2) The study included a comparison of injury rates of morning, afternoon and night shifts. Especially studies in summary tables fill the criteria.

3) In the part of extended working days all studies related to occupational safety during extended working days were included in the text. However, only studies including exact injury rates of 8 working hours compared to 10 hours, 12 hours or longer working hours were presented at the Table 2.

\section{SHIFT WORK AS RISK FACTOR}

In a review of 19 studies 8 showed a higher frequency of accidents during night shifts, one during day shifts, two during morning shifts and two during afternoon shifts. In six studies there were no differences between day and night shifts [1].

*Address correspondence to this author at the Finnish Institute of Occupational Health, Helsinki, Finland; Tel: +358-30-474 2731; Fax: +35830-474 2020; E-mail: simo.salminen@ttl.fi
The recent review showed that compared to morning shifts, the risk of occupational injury during afternoon shifts increased by $18.3 \%$ and in night shifts by $30.4 \%$. This review is based on five studies published between years of 1972 and 1995 [2, 3]. However, the authors [4-6] later added two studies to their review, and concluded that the risk of occupational injury was $15 \%$ higher during afternoon shifts and $28 \%$ higher during night shifts compared to morning shifts. When they examined successive night shifts, the risk of occupational injury was $6 \%$ higher on the second night, $17 \%$ higher on the third night, and 36\% higher on the fourth night. As regards to day shifts, the risk increased by $2 \%$ for the second morning, $7 \%$ for the third morning, and $17 \%$ for the fourth morning. The effect of older age on the relationship of shift work and occupational injuries is not yet proven [7].

Outside these reviews, a study of workers of a large English engineering company showed that during afternoon shifts the risk of occupational injury was $15 \%$ higher, and during night shifts $23 \%$ higher than during morning shifts. Moreover, injuries in the self-paced work were more serious on the night shift compared with the morning shift [8].

Driving home after a night shift increased the risk of fatigue-related traffic accidents [9]: a systematic review concluded that the risk of crashing doubles after extended shifts [10].

Employees of evening and night shifts had a respectively higher risk of occupational injury at $43 \%$ and $30 \%$ compared to conventional day shifts according to the National Longitudinal Survey of Youth. In addition, rotating shift work increased injury risk by $36 \%$ and irregular shift work by $15 \%$ [11]. The greatest risk of occupational injury in evening shifts was found among construction workers [12].

In a metallurgic plant in the former German Democratic Republic, occupational injuries reached a maximum during night shifts [13]. In an American paint company, the 
incidence rate was $6 \%$ lower than the paint industry on average. However, workers had a $25 \%$ greater injury rate during night shifts than during morning shifts, and the injury risk was highest in the last three hours of the night shift [14]. Occupational injuries occurred most often in the fourth working hour during the morning shifts and the fifth and sixth hour during night shift in Indian textile industries [15]. Fire fighters from a Northeastern state were injured more often during the night shifts and during meal-times [16].

In a Canadian glass factory and steel plant, injuries peaked at noon, just before lunch time and between 2 and 4 a.m. during the night shift [17]. During afternoon and night shifts, injuries were less severe than in the morning shift in six automotive plants in Ontario, Canada [18]. However, injuries were more serious during night shifts, although the injury rate was lower during night shifts than during the morning and afternoon shifts in an iron and steel plant in Singapore [19].

Dutch bus drivers suffered injury more often during the morning shift than the afternoon shift. Starting early particularly increased the risk, so that the peak was during the fourth hour of the shift [20]. In Norwegian drilling rigs, operators had more injuries during the day shift than during the night shift, due to higher activity level and more people working at day time. However, there was no difference between day and night shifts in the injury rate among drilling crews [21].

In Australia, the risk of fatal occupational injury was double during the night shift compared to other shifts [22]. Female adolescents working on night shift in Queensland, Australia, were involved in occupational injuries almost five times more often than their adult counterparts, whereas male adolescents injured three times more often than adult males [23].

The effect of rotating shift work on occupational injuries was examined in three studies. Working in rotating shifts with nights also doubled the risk of occupational injury among New Zealand Blood Donors [24]. In a large German electronic factory, employees in rotating shifts had 34\% more injuries than employees in day shifts [25]. However, a fixed-term shift system was superior in performance to the rotating shift system in a resistor manufacturing company in Taiwan [26].

Extreme morning-types suffered more from shift work than their evening-type counterparts [27]. In a Turkish margarine production factory, accidents declined after the change from two-day rotation to weekly rotation [28]. This shows that night work should be reduced as much as possible, and perhaps replaced by quickly rotating shift systems [29].

The review of Folkard and Åkerstedt [3] is based on studies published from 1962 to 1995 , and the oldest studies in the review did not report exact results. That is why I have carried out the same review on more recent studies.

Table 1 summarizes the main details of the studies relating to the trend across the three shifts. The risk of occupational injury during morning shifts was set at 1.0 and the relative risk during afternoon shifts was calculated by dividing the injury frequency of the afternoon shift by the frequency of the morning shift. The same calculation was also carried out for night shifts.

The new review showed that the risk of occupational injury was $6 \%$ lower during afternoon shifts than morning shifts (Table 1). However, it is important to note the difference between the USA and developing countries. In the USA, workers of afternoon shifts had a $31 \%$ higher risk of occupational injury, whereas in the developing countries the risk during afternoon shifts was almost half $(57 \%)$ that of morning shifts.

The analysis showed that the risk of occupational injury during night shifts was $15 \%$ lower than during morning shifts (Table 1). Once again, the risk was $30 \%$ higher during the night shifts in American companies, but in developing countries, the risk of occupational injury during night shifts was $60 \%$ lower than during morning shifts.

The results of my review are in line with the review of Folkard and Åkerstedt [3], if we focus on results from the USA. For the afternoon shifts I found a slightly higher risk of occupational injury than Folkard and Åkerstedt, but for night shifts the risk level was the same in both reviews. However, the new results from developing countries changed the overall situation, when both afternoon and night shifts had a lower accident frequency than morning shifts. One reason for this could be that there are fewer supervisors during afternoon and nights shifts and accidents are not registered as often as during morning shifts.

One critical question regarding the effect of shift work on occupational injuries is whether the employees permanently worked evening or night shifts or worked by rotating shifts. In two studies $[14,19]$ they worked in rotating shifts,

Table 1. Summary of Studies Reporting Incidents Across Three Shifts

\begin{tabular}{|c|c|c|c|c|c|}
\hline Authors & Industry & Country & Morning & Afternoon & Night \\
\hline \hline Levin [14] & Paint manuf. & USA & 1.00 & 1.16 & 0.53 \\
\hline Ong [19] & Iron \& Steel & Singapore & 1.00 & 0.60 & 0.41 \\
\hline Nag [15] & Textile & India & 1.00 & 1.45 & 0.41 \\
\hline Dembe [11] & NLSY & USA & 1.00 & 1.94 & 1.31 \\
\hline Average & & & 1.00 & 0.85 \\
\hline USA & & & 1.00 & 0.57 & 1.30 \\
\hline Developing & countries & & 0.41 \\
\hline
\end{tabular}


Table 2. Summary of the Studies Across Hours on Duty

\begin{tabular}{|c|c|c|c|c|c|c|}
\hline Author & Industry & Country & $8 \mathrm{~h}$ & $10 \mathrm{~h}$ & $12 \mathrm{~h}$ & $12>h$ \\
\hline Laundry [34] & Textile & Canada & 1.00 & - & 0.55 & - \\
\hline Hänecke [44] & All & Germany & 1.00 & 1.69 & 1.92 & 2.23 \\
\hline Johnson [35] & Manufact. & USA & 1.00 & - & 1.01 & - \\
\hline Baker [36] & Coal mine & Australia & 1.00 & - & 0.34 & \\
\hline Dong [42] & Construction & USA & 1.00 & 1.18 & 1.98 & - \\
\hline Dembe [43] & NLSY & USA & 1.00 & - & 1.38 & 1.84 \\
\hline Allen [46] & Heavy man & USA & 1.00 & 1.58 & 0.73 & - \\
\hline Vegso [45] & Metal & USA & 1.00 & 1.19 & 1.21 & 1.88 \\
\hline Average & & & 1.00 & 1.41 & 1.14 & 1.98 \\
\hline
\end{tabular}

whereas in the other two studies $[11,15]$ employees worked only evening or night shifts. However, permanently working evening and night shifts or in rotating shifts did not seem to influence injury rates.

\section{EXTENDED WORKING DAYS AND OCCUPATIONAL ACCIDENTS}

Extended working days are referring to working more than 48 hours per week [30]. Per a study in Australia, the primary reasons for employers to introduce 12-hour shifts are financial and productivity considerations [31].

In their review, Duchon and Smith [32] found that in six out of seven studies, long working hours increased the number of occupational accidents, while in one study accidents decreased after the change to 12-hour shifts. In the later review of 49 studies, Bendak [33] concluded that most workers preferred 12-hour shifts than 8-hour shifts although most of the objective performance measures showed negative effects. The extra 4 hours increased fatigue, which may in turn lead to an increased accident risk. Folkard and Lombardi [5] concluded that, based on four studies, 10-hour shifts increased the injury risk by $13 \%$ and 12 -hour shifts by $28 \%$ compared to the risks of an 8-hour working day. According to these reviews, extended working days increased the risk of occupational injury.

A change from a three 8-hour shift system to a two 12hour shift system in a Canadian synthetic yarn manufacturing company decreased the occupational injury rate, but did not influence off-the-job injuries [34]. The workers of a large American manufacturing site preferred the change from 8-hour/7-day rotating shifts to 12 -hour rotating shifts, because of subjective feelings regarding health and family life. However, the change had no effect on the occupational injury rate [35]. In an Australian coal mine, a change from an 8-hour/7-day roster to a 12-hour/7-day schedule decreased accident frequency in a coal preparation plant, but increased absenteeism in the maintenance department [36]. When workers of an Australian power station [37] and an American nuclear power station [38] moved from an 8-hour roster to a 12-hour roster, operator errors increased. In an American police station, on the other hand, the change from 8-hour shifts to 12-hour shifts improved organizational effectiveness and decreased the stress and fatigue of police officers [39]. To conclude, two studies showed that the change to longer working days decreased the occupational injury rate, and one showed no changes.

In a Canadian underground metal mine, workers changed from seven by two 8-hours schedule to a four by four 12hour shift schedule. An overwhelming majority of workers supported the change, because it improved sleep quality. No changes were found in fatigue-sensitive behavioral and physiological performance measures [40], and older workers in the same mine had no more difficulties with a 12-hour shift than with an 8-hour schedule [41]. This study, in line with other studies, supported the claim that the majority of workers prefer 12-hour shifts due to improved sleep and family life.

Based on the National Longitudinal Survey of Youth, Dong [42] found that among construction workers, working over 50 hours per week increased the risk of occupational injury. The risk was double for those working over 60 hours per week compared to those working 40 hours. Based on the same data set, Dembe, Erickson, Delbos and Banks [43] showed that working at least 12 hours per day increased the risk of occupational injury by $37 \%$. Working over 60 hours per week raised the injury risk by $23 \%$, whereas working in a job with overtime (for overtime pay) increased it by $61 \%$. Working overtime increased the risk of occupational injury among professional, technical and managerial personnel in particular [12]. These results showed that working overtime, especially over 60 hours per week, dramatically increased the risk of occupational injury.

The risk of occupational injury increased exponentially beyond the 9th work hour among German workers. After 12 hours the risk was double compared to the first eight working hours [44]. American metal workers who worked over 64 hours per week had an $88 \%$ higher risk of occupational injury than those working 40 hours per week [45]. A survey of American workers showed that those working over 60 hours per week were more likely to report occupational injuries [46]. These studies show that the risk of occupational injury is almost double when working hours exceed 60 per week compared to 40 hours per week.

Table 2 shows the main details of the 8 studies relating to extended work days. The risk of occupational injury in an 8 hour working day was set at 1.0 and the relative risk of a 10- 
hour working day was calculated by dividing the injury frequency of the 10-hour working day by the frequency of the 8-hour working day. The same calculation was made for working days of 12 hours and over. Only studies with exact injury rates were included in the Table 2.

Based on four studies, the review showed that the risk of occupational injury was $41 \%$ higher for 10 -hour working days compared to 8-hour working days (Table 2). Twelve comparisons were found between 8-hour and 12-hour working days, showing that working 12 hours increased the risk of occupational injury by $14 \%$. Three studies showed a $98 \%$ increase in occupational injuries when working more than 12 hours per day.

Compared to the review of Folkard and Lombardi [5], this review showed a higher increased risk of occupational injury during a 10 -hour working day than during an 8-hour shift. The newest study [46] in particular showed a high increase in the risk of injury during 10-hour shifts. On the other hand, I found a lower risk of occupational injury during 12-hour shifts than Folkard and Lombardi [5]. I used 8 studies compared to the four studies in their review, three of which $[34,36,46]$ showed a lower risk of injury during a 12-hour working day than during an 8-hour working day.

One critical point for occupational safety is to note that the risk of occupational injury is highest during the last working hour on an extended working day [5, 42-44]. As this is an exception to the hourly distribution of occupational injuries during the 8-hour work shift, it shows the hazardousness of extended working hours more clearly. It is recommended that employees work 8-hours per day for a longer period if necessary, rather than extended working days for a shorter time period.

\section{THE EFFECT OF REST BREAKS}

In his review, Tucker [47] concluded, based on six studies, that rest breaks are an effective means of controlling the accumulation of accidents during industrial shift work. However, he wrote that there is only limited direct epidemiological evidence on the effects of rest breaks on accident occurrence. The risk of occupational injury increased during the second and third half-hours after the break in a large engineering company in the US and among patients of traumatic occupational hand injuries [48]. On the other hand, at a car assembly plant in the United Kingdom, the accident risk rose significantly during the fourth halfhour after the break, and fell immediately after the break [49]. The results of these studies supported the present system in which workers take a break after two hours of work.

\section{DISCUSSION}

Increasing flexibility in work life also means working longer hours in order to increase productivity. On the other hand, workers are no longer tied to their work all the time, or to one particular place. This flexibility also requires workers to maintain their work capacity themselves, which MacEachen, Polzer and Clarke [50] called "strategies of resilience".

In conclusion, this review showed that extended work hours increased the risk of occupational injury. Especially working over 12 hours per day doubled the risk of injury. Extended working days may be suitable, if the nature of the work and the workload allow it [29].

On the other hand, afternoon and night increased the risk of occupational injury compared to morning shift in industrialized countries. A new finding was that in the developing countries the situation is vice versa; the injury frequency was higher in morning shifts than in afternoon and night shifts. One possible explanation is the lack of supervisors during afternoon and nights shifts, and that is why more injuries were not reported during afternoon and night shifts. Both stimulus and transactional models of stress explained the link between shift work and health [51].

\section{REFERENCES}

[1] Costa G. The impact of shift and night work on health. Appl Ergon 1996; 27(1): 9-16.

[2] Folkard S, Tucker P. Shift work, safety and productivity. Occup Med 2003; 53: 95-101

[3] Folkard S, Åkerstedt T. Trends in the risk of accidents and injuries and their implications for models of fatigue and performance. Aviation Space Environ Med 2004; 75(3): A161-7.

[4] Folkard S, Lombardi DA, Tucker, PT. Shiftwork: safety, sleepiness and sleep. Ind Health 2005; 43: 20-3.

[5] Folkard S, Lombardi DA. Modeling the impact of the components of long work hours on injuries and "accidents". Amer J Ind Med 2006; 49: 953-63.

[6] Folkard S, Lombardi DA, Spencer MB. Estimating the circadian rhythm in the risk of occupational injuries and accidents. Chronobiol Int 2006; 23(6): 1181-92.

[7] Folkard S. Shift work, safety, and aging. Chronobiol Int 2008; 25(2\&3): 183-98.

[8] Smith L, Folkard S, Poole CJM. Increased injuries on night shift. Lancet 1994; 344: 1137-9.

[9] Monk TH, Folkard S, Wedderburn AI. Maintaining safety and high performance on shiftwork. Appl Ergon 1996; 27(1): 17-23.

[10] Robb G, Sultana S, Ameratunga S, Jackson R. A systematic review of epidemiological studies investigating risk factors for workrelated road traffic crashes and injuries. Injury Prev 2008; 14(1): 51-8.

[11] Dembe AE, Erickson JB, Delbos RG, Banks SM. Nonstandard shift schedules and the risk of job-related injuries. Scand J Work Environ Health 2006; 32(3): 232-40.

[12] Dembe AE, Delbos R, Erickson JB. The effect of occupation and industry on the injury risks from demanding work schedules. J Occup Environ Med 2008; 50(10): 1185-94.

[13] Quaas M, Tunsch R. Problems of disablement and accident frequency in shift- and night work. In: Proceedings of the Second International Symposium on Night and Shift Work Slanchev Bryag, September 20-24, 1971. Studia Laboris et Salutis, Report no. 11. Stockholm: National Institute of Occupational Health 1972; pp. 52-7.

[14] Levin L, Oler J, Whiteside JR. Injury incidence rates in a paint company on rotating production shifts. Accid Anal Prev 1985; 17(1): 67-73

[15] Nag PK, Patel VG. Work accidents among shiftworkers in industry. Int J Ind Ergon 1998; 21(3-4): 275-81.

[16] Glazner LK. Factors related to injury of shiftworking fire fighters in the Northeastern United States. Saf Sci 1996; 21(3): 255-63.

[17] Wojtczak-Jaroszowa J, Jarosz D. Time-related distribution of occupational accidents. J Saf Res 1987; 18: 33-41.

[18] Barsky I, Dutta SP. Age, shiftwork and industrial accidents - a longitudinal study. In: Kumar S, Ed. Advances in Industrial Ergonomics and Safety IV. London: Taylor \& Francis 1992; pp. 113-20.

[19] Ong CN, Phoon WO, Iskandar N, Chia KS. Shiftwork and work injuries in an iron and steel mill. Appl Ergon 1987; 18(1): 51-6.

[20] Pokorny MLI, Blom DH, van Leeuwen P. Shifts, duration of work and accident risk of bus drivers. Ergon 1987; 30(1): 61-88.

[21] Lauridsen O, Tønnesen T. Injuries related to the aspects of shift working - a comparison of different offshore shift arrangements. J Occup Accid 1990; 12: 167-76. 
[22] Williamson AM, Feyer A-M. Causes of accidents and the time of day. Work Stress 1995; 9(2-3): 158-64.

[23] Loudoun R, Allan C. The effect of time of day on injury patterns amongst adolescents in Australia. Appl Ergon 2008; 39: 663-70.

[24] Fransen M, Wilsmore B, Winstanley J, et al. Shift work and work injury in the New Zealand Blood Donors' Health Study. Occup Environ Med 2006; 63: 352-8.

[25] Ott MG, Oberlinner C, Lang S, et al. Health and safety protection for chemical industry employees in a rotating shift system: program design and acute injury and illness experience at work. J Occup Environ Med 2009; 51: 221-31.

[26] Liou T-S, Wang M-JJ. Rotating-shift system $v s$ fixed-shift system. Int J Ind Ergon 1991; 7: 63-70.

[27] Monk TH. Shiftwork and safety. Prof Saf 1989; 34(4): 26-30.

[28] Bell CR, Telman N. Errors, accidents and injuries on rotating shiftwork: a field study. Int Rev Appl Psychol 1980; 29: 271-91.

[29] Knauth P. Designing better shift systems. Appl Ergon 1996; 27(1): 39-44.

[30] Harrington JM. Health effects of shift work and extended hours of work. Occup Environ Med 2001; 58: 68-72.

[31] Loudoun R, Harley B. Industrial relations: decentralisation and the growth of 12-hour shifts in Australia. J Ind Relat 2001; 43(4): 40221 .

[32] Duchon JC, Smith TJ. Extended workdays and safety. Int J Ind Ergon 1993 ;11(1): 37-49.

[33] Bendak S. 12-h workdays: current knowledge and future directions. Work Stress 2003; 17(4): 321-36.

[34] Laundry BR, Lees REM. Industrial accident experience of one company on 8- and 12-hour shift systems. J Occup Med 1991; 33(8): 903-6.

[35] Johnson MD, Sharit J. Impact of a change from an 8-h to a 12-h shift schedule on workers and occupational injury rates. Int J Ind Ergon 2001; 27: 303-19.

[36] Baker A, Heiler K, Ferguson SA. The impact of roster changes on absenteeism and incident frequency in an Australian coal mine. Occup Environ Med 2003; 60: 43-9.

[37] Mitchell RJ, Williamson AM. Evaluation of an 8 hour versus a 12 hour shift roster on employees at a power station. Appl Ergon $2000 ; 31: 83-93$
[38] Baker K, Olson J, Morisseau D. Work practices, fatigue, and nuclear power plant safety performance. Human Fact 1994; 36(2): 244-57.

[39] Pierce JL, Dunham RB. The 12-hour work day: a 48-hour, eightday week. Acad Manag J 1992; 35(5): 1086-98.

[40] Duchon JC, Keran CM, Smith TJ. Extended workdays in an underground mine: a work performance analysis. Human Fact 1994; 36(2): 258-68.

[41] Keran CM, Duchon JC, Smith TJ. Older workers and longer work days: are they compatible? Int J Ind Ergon 1994; 13(2): 113-23.

[42] Dong X. Long workhours, work scheduling and work-related injuries among construction workers in the United States. Scand J Work Environ Health 2005; 31(5): 329-35.

[43] Dembe AE, Erickson JB, Delbos RG, Banks SM. The impact of overtime and long work hours on occupational injuries and illnesses: new evidence from the United States. Occup Environ Med 2005; 62: 588-97.

[44] Hänecke K, Tiedemann S, Nachreiner F, Grzech-Sukalo $H$. Accident risk as a function of hour at work and time of day as determined from accident data and exposure models for the German working population. Scand J Work Environ Health 1998; 24(Suppl 3): 43-8.

[45] Vegso S, Cantley L, Slade M, et al. Extended work hours and risk of acute occupational injury: a case-crossover study of workers in manufacturing. Am J Ind Med 2007; 50(8): 597-603.

[46] Allen HM, Slavin T, Bunn WB. Do long workhours impact health, safety, and productivity at a heavy manufacturer? J Occup Environ Med 2007; 49(2): 148-71.

[47] Tucker P. The impact of rest breaks upon accident risk, fatigue and performance: a review. Work Stress 2003; 17(2): 123-37.

[48] Tucker P, Lombardi D, Smith L, Folkard S. The impact of rest breaks on temporal trends in injury risk. Chronobiol Int 2006; 23(6): 1423-34.

[49] Tucker P, Folkard S, Macdonald I. Rest breaks and accident risk. Lancet 2003; 361: 680 .

[50] MacEachen E, Polzer J, Clarke J. "You are free to set your own hours"; Governing worker productivity and health through flexibility and resilience. Soc Sci Med 2008; 66(5): 1019-33.

[51] Taylor E, Briner RB, Folkard S. Models of shiftwork and health: An examination of the influence of stress on shiftwork theory. Human Fact 1997; 39(1): 67-82.

Received: March 27, 2009

Revised: December 10, 2009

Accepted: January 7, 2010

(C) Simo Salminen; Licensee Bentham Open .

This is an open access article licensed under the terms of the Creative Commons Attribution Non-Commercial License (http: //creativecommons.org/licenses/ by-nc/3.0/) which permits unrestricted, non-commercial use, distribution and reproduction in any medium, provided the work is properly cited. 